\title{
QUANTITATION OF GENISTEIN AND GENISTIN IN SOY DRY EXTRACTS BY UV-VISIBLE SPECTROPHOTOMETRIC METHOD
}

Isabela da Costa César*, Fernão Castro Braga, Cristina Duarte Vianna-Soares, Elzíria de Aguiar Nunan, Gérson Antônio
Pianetti e Ligia Maria Moreira-Campos
Departamento de Produtos Farmacêuticos, Faculdade de Farmácia, Universidade Federal de Minas Gerais, Av. Pres. Antônio Carlos, 6627, 31270-901 Belo Horizonte - MG, Brasil

Recebido em 4/5/07; aceito em 1/7/08; publicado na web em 5/11/08

\begin{abstract}
This paper describes the development and validation of an UV-Visible spectrophotometric method for quantitation of genistein and genistin in soy dry extracts, after reaction with aluminum chloride. The method showed to be linear $\left(r^{2}=0.9999\right)$, precise (R.S.D. < $2 \%$ ), accurate (recovery of $101.56 \%$ ) and robust. Seven samples of soy dry extracts were analyzed by the spectrophotometric validated method and by RP-HPLC. Genistein concentrations determined by spectrophotometry $(0.63 \%-16.05 \%)$ were slightly higher than values obtained by HPLC analysis $(0.40 \%-12.79 \%)$; however, the results of both methods showed a strong correlation.
\end{abstract}

Keywords: isoflavones; spectrophotometry; RP-HPLC.

\section{INTRODUCTION}

Phytoestrogens are plant natural products regarded to possess estrogenic effects. Soy isoflavones are the most frequently used phytoestrogens and have received large attention over the last years due to their potential ability to reduce the symptoms associated to menopause. ${ }^{1}$ Additionally, they are considered effective to prevent chronic pathologies such as osteoporosis, cardiovascular diseases and hormone-related cancers. ${ }^{2}$ Hence, soy dry extracts have been widely employed as pharmaceutical raw materials for manufacturing isoflavone supplements, used for the treatment of menopausal symptoms and the above mentioned chronic diseases.

Daidzein and genistein are the major isoflavones found in soy extracts, along with the minor product glycitein (Figure1). They also occur naturally in soy as their glycosides, named daidzin, genistin and glycitin, respectively. ${ }^{3}$ When orally administered, isoflavones glycosides undergo enzymatic hydrolysis in the small intestine, releasing the aglycones, the moieties which are absorbed and present biologic effects. ${ }^{4}$ In vitro studies for these aglycones have demonstrated that genistein exhibits the highest affinity for estrogenic receptors, ${ }^{5}$ being approximately ten times more active in vivo than daidzein. ${ }^{6}$ Therefore, genistein can be accounted as the main isoflavone responsible for the biological activity of soy extracts.<smiles>O=c1c(-c2ccc(O)cc2)coc2cc(O)cc(O)c12</smiles><smiles>O=c1c(-c2ccc(O)cc2)coc2cc(OC3OC(CO)C(O)C(O)C3O)cc(O)c12</smiles>

Genistein<smiles>O=c1c(-c2ccc(O)cc2)coc2cc(O)ccc12</smiles><smiles>COc1cc2c(=O)c(-c3ccc(O)cc3)coc2cc1O</smiles>

Figure 1. Chemical structures of isoflavones

*e-mail: isaccesar@bol.com.br
Many methods reported in literature for the analysis of soy isoflavones are based on high performance liquid chromatography (HPLC) ${ }^{7-}$ ${ }^{10}$ and gas chromatography-mass spectrometry (GC-MS). ${ }^{11-14}$ They have been developed to quantify several isoflavones simultaneously, however, involve laborious processes of sample preparation, separation, detection and data analyses. We have recently developed and validated a RP-HPLC method for quantifying isoflavone aglycones released after acid hydrolysis and demonstrated its application for quantifying isoflavone aglycones in the analysis of soy dry extract samples used as pharmaceutical raw material. ${ }^{15}$

Some methods reported in literature ${ }^{16}$ and pharmacopoeias ${ }^{17,18}$ to the assay of flavonoids are based on the UV absorbance determination of the resulting complex with aluminum chloride $\left(\mathrm{AlCl}_{3}\right)$. Flavonoids containing 5-hydroxy-4-keto, 3-hydroxy-4-keto or $O$-dihydroxyl systems are able to chelate with $\mathrm{AlCl}_{3}$ and the reaction is disclosed by a bathochromic shift of the bands in the UV-Visible spectrum..$^{19,20}$ Among the major isoflavones found in soy extracts, only genistein and its glycoside, genistin, present the structural feature required to react with $\mathrm{AlCl}_{3}$. As far as we know, no spectrophotometric method for the quantitative assay of genistein or other isoflavones has been reported to date.

The increasing consumption of soy extract as pharmaceutical products and supplements demands the development of alternative methods for the routine analysis of soy isoflavones. Within this context, the aim of this study was to develop and validate a simple and rapid UV-Visible method to quantify genistein and its glycoside genistin in soy dry extracts, after reaction with $\mathrm{AlCl}_{3}$. Samples of soy dry extract were analyzed by the developed method and the results obtained were statistically compared with those previously determined by RP-HPLC. ${ }^{15}$

\section{EXPERIMENTAL}

\section{Reagents and materials}

Genistein reference compound was purchased from ChromaDex (Santa Ana, CA, USA). Seven samples of soy dry extracts standardized to contain $40 \%$ (w/w) of total isoflavones, from six different suppliers, were kindly donated by compounding pharmacies from 
Belo Horizonte, MG, Brazil. Two batches of supplier 2 were assayed. Methanol and acetic acid were purchased from Merck (Darmstadt, Germany) and aluminum chloride (analytical reagent grade) was obtained from Sigma (St. Louis, MO, USA).

\section{Instrumental and analytical conditions}

UV-Visible spectrophotometric analyses were carried out on a Shimadzu UV160A spectrophotometer. After reaction with $\mathrm{AlCl}_{3}$, the UVVisible spectrum of genistein and soy dry extract solutions were recorded in the range of 200 to $500 \mathrm{~nm}$. In the spectral analysis, the wavelength $382 \mathrm{~nm}$ was defined for the quantitation of genistein and genistin in soy dry extract samples. The time interval for recording the UV spectrum after complex formation was also investigated to determinate the optimal time for reaction and to evaluate the complex stability. Hence, spectrophotometric determination of soy dry extract solutions was carried out immediately after the $\mathrm{AlCl}_{3}$ addition and at regular intervals of $10 \mathrm{~min}$, until $240 \mathrm{~min}$. The interval time of $10 \mathrm{~min}$ was defined for measuring absorbance of solutions after $\mathrm{AlCl}_{3}$ addition.

The HPLC analyses were carried out on an HP1100 system Agilent (Santa Clara, CA, USA), composed of quaternary pump, auto sampler, photodiode array detector (DAD) and HP ChemStation software. The chromatographic conditions employed were previously described by César et al.. ${ }^{15}$ A C18 endcapped Lichrospher column ( 250 x $4.6 \mathrm{~mm}$ I.D.; $5 \mu \mathrm{m}$ particle size) was employed (Merck, Darmstadt, Germany), at $30{ }^{\circ} \mathrm{C}$. The mobile phase was composed of $0.1 \%$ acetic acid and methanol (52:48), at a flow rate of $1.0 \mathrm{~mL} / \mathrm{min}$. The injection volume was $20 \mu \mathrm{L}$ and UV-detection was performed at $254 \mathrm{~nm}$.

\section{Preparation of solutions for spectrophotometric analysis}

Genistein standard solution: approximately $15 \mathrm{mg}$ of genistein reference compound were accurately weighed in a $100 \mathrm{~mL}$ volumetric flask. Methanol $(80 \mathrm{~mL}$ ) was added, the solution was sonicated for 5 min and volume was adjusted to $100 \mathrm{~mL}$ with methanol. An aliquot (5 $\mathrm{mL})$ was transferred to a volumetric flask $(25 \mathrm{~mL})$ and $1 \mathrm{~mL}$ of $\mathrm{AlCl}_{3}$ $2 \%(\mathrm{w} / \mathrm{v})$ in methanol was added. The flask volume was completed with methanol, to obtain a solution at $30 \mu \mathrm{g} / \mathrm{mL}$.

Soy dry extract sample solution: approximately $50 \mathrm{mg}$ of soy dry extract sample, previously dried at $105^{\circ} \mathrm{C}$ for $4 \mathrm{~h}$, were accurately weighed in a $50 \mathrm{~mL}$ volumetric flask. Methanol $(40 \mathrm{~mL})$ was added and the solution was sonicated for $5 \mathrm{~min}$. The volume was adjusted to $50 \mathrm{~mL}$ with methanol and filtered. An aliquot of the solution $(5 \mathrm{~mL})$ was transferred to a volumetric flask $(25 \mathrm{~mL})$ and $1 \mathrm{~mL}$ of $\mathrm{AlCl}_{3} 2 \%(\mathrm{w} / \mathrm{v})$ in methanol was added. The flask volume was completed with methanol.

Blank solutions for genistein standard and soy dry extract sample solutions were similarly prepared, without the addition of $\mathrm{AlCl}_{3}$.

\section{Validation of the spectrophotometric method}

The optimized method was validated according to ICH guidelines for the validation of analytical methods. ${ }^{21}$

\section{Linearity}

Three replicates of genistein standard solutions at $150 \mu \mathrm{g} / \mathrm{mL}$ were diluted in methanol to six different concentrations $(1.5 ; 6 ; 18 ; 30 ; 42$ and $54 \mu \mathrm{g} / \mathrm{mL})$. An aliquot $(1 \mathrm{~mL})$ of $\mathrm{AlCl}_{3} 2 \%(\mathrm{w} / \mathrm{v})$ in methanol was added to each diluted solution. A calibration curve for concentration versus absorbance was plotted and the obtained data were subjected to regression analysis using the Least Square Method.

\section{Precision}

The intra-day precision was evaluated by analyzing six replicates of soy dry extract solutions ( $n=6)$, at $100 \%$ of the test concentration (30 $\mu \mathrm{g} / \mathrm{mL}$ ). Similarly, the inter-day precision was evaluated in two consecutive days $(n=12)$. The concentration of genistein in soy dry extracts was determined after reaction with $\mathrm{AlCl}_{3}$, and the relative standard deviation (R.S.D.) was calculated.

\section{Accuracy}

Standard solutions of genistein, at three different concentration levels, were added to soy dry extracts samples before reaction with $\mathrm{AlCl}_{3}$. At each level, solutions were prepared in triplicate and the recovery percentage was determined.

\section{Specificity}

It was evaluated regarding the presence of other major isoflavones (daidzein and glycitein) in soy dry extracts. Solutions of those isoflavones were prepared at $30 \mu \mathrm{g} / \mathrm{mL}$, following addition of $1 \mathrm{~mL}$ of $\mathrm{AlCl}_{3} 2 \%(\mathrm{w} / \mathrm{v})$ in methanol. The UV-Visible spectra were recorded in the range of 200 to $500 \mathrm{~nm}$, to evaluate the presence of absorption band at $382 \mathrm{~nm}$, indicative of complex formation.

\section{Robustness}

Six sample solutions were prepared and analyzed using the established conditions and by variation of the following analytical parameters: added volume of $\mathrm{AlCl}_{3}$ solution (0.5-1.5 mL) and two methanol suppliers. Genistein contents and R.S.D. were determined for each condition. The obtained data were submitted to statistical analysis (Student- $t$ test) at 0.05 significance level.

\section{Detection and quantitation limits}

Diluted genistein standard solutions were analyzed, at decreasing concentrations, in the range of 1.00 to $0.10 \mu \mathrm{g} / \mathrm{mL}$. To assess the limit of detection, absorbance values and UV-Visible spectra were evaluated, whereas the quantitation limit was settled as the lower concentration which provided responses with adequate linearity and precision (R.S.D. $<2.0 \%$ ). The detection and quantitation limits were also calculated by the standard deviation and the slope of the calibration curve and the values were compared with those obtained by the response of the diluted solutions.

\section{Analysis of soy dry extracts samples}

Seven commercial samples of soy dry extract were analyzed using the developed spectrophotometric method and the RP-HPLC method described by César et al.. ${ }^{15}$ Samples solutions were prepared in quintuplicate for the spectrophotometric analyses, as described in Soy dry extract sample solution. Solution absorbances were recorded at 382 $\mathrm{nm}, 10 \mathrm{~min}$ after $\mathrm{AlCl}_{3}$ addition, employing the correspondent blank solutions as reference. For the chromatographic analyses, $50 \mathrm{mg}$ of soy dry extract were accurately weighed in a $100 \mathrm{~mL}$ volumetric flask, in quintuplicate, following the addition of $3.0 \mathrm{M} \mathrm{HCl}$ in ethanol $(80 \mathrm{~mL})$. The solution was sonicated for $5 \mathrm{~min}$ and submitted to steam bath for $40 \mathrm{~min}$. The flask volume was completed, and $5 \mathrm{~mL}$ were transferred to a $25 \mathrm{~mL}$ volumetric flask. The volume was completed with mobile phase and $20 \mu \mathrm{L}$ were injected onto the chromatograph.

\section{RESULTS AND DISCUSSION}

The UV-Visible spectrum recorded for a solution of genistein after reaction with $\mathrm{AlCl}_{3}$ showed an intense absorption band with maximum wavelength at $382 \mathrm{~nm}$, which was not found in the UV-Visible spectrum of genistein alone (Figure 2). As expected, this absorption band indicates complex formation between genistein and $\mathrm{AlCl}_{3}$. A similar absorption band was present in the UV-Visible spectrum of a soy dry 
extract solution, after reaction with $\mathrm{AlCl}_{3}$, attesting the presence of genistein and its glycoside in the analyzed sample.

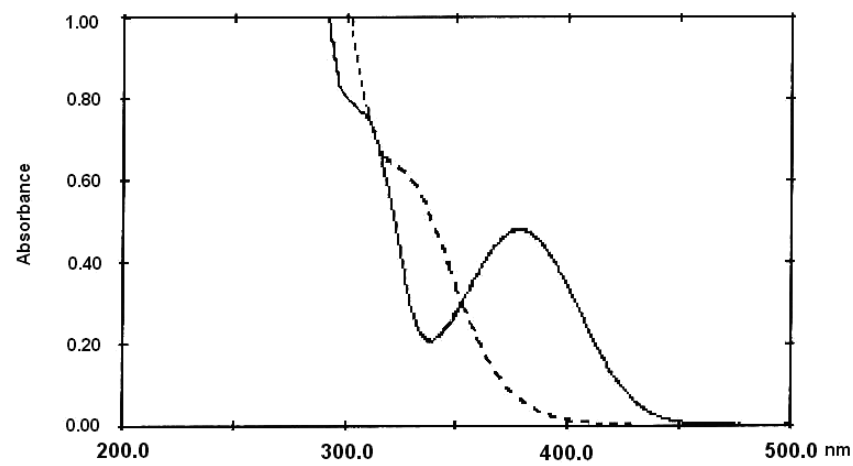

Figure 2. UV-Visible spectra of genistein in presence of $\mathrm{AlCl}_{3}$ (full line) and absence of $\mathrm{AlCl}_{3}$ (broken line) in methanol

The time interval for spectrophotometric detection of the complex was evaluated. The UV absorbance of genistein $/ \mathrm{AlCl}_{3}$ product reaches its maximum after $5 \mathrm{~min}$ of reaction. Its stability was observed to last for $240 \mathrm{~min}$, since no significant variation in absorption was detected during this period. Based on these findings, a period of $10 \mathrm{~min}$ after $\mathrm{AlCl}_{3}$ addition was defined as the optimal detection time for quantitation of genistein and genistin in soy dry extract samples.

\section{Validation of the spectrophotometric method}

\section{Linearity}

A linear correlation $\left(r^{2}=0.9999\right)$ was found between the absorbance values and the concentration of genistein solutions, after reaction with $\mathrm{AlCl}_{3}$, in the assayed range. The regression analysis data are shown in Table 1. The significance of the intercept obtained in the calibration curve was tested and this parameter was not statistically significant $(p>0.05)$. Hence, it can be considered that the curve passes through the origin. The low R.S.D. value $(0.76 \%)$ indicated the high precision of the calibration curve.

Table 1. Overview of the linearity data obtained for genistein, after reaction with $\mathrm{AlCl}_{3}$

\begin{tabular}{lc}
\hline Parameters & Regression analysis results \\
\hline Regression coefficient & 0.9999 \\
Slope \pm standard deviation & $0.0143 \pm 0.0001$ \\
Intercept \pm standard deviation & $0.0004 \pm 0.0011$ \\
Relative standard deviation $(\%)$ & 0.76 \\
Concentration range $(\mu \mathrm{g} / \mathrm{ml})$ & $1.5-54$ \\
Number of points & 6 \\
\hline
\end{tabular}

\section{Precision}

In the intra-day precision analyses $(n=6)$, the mean content of genistein and genistin, expressed as genistein, was $15.83 \%$ (R.S.D. $=0.65 \%)$. For the inter-day precision $(n=12)$, the obtained mean was $15.95 \%$ (R.S.D. $=1.16 \%$ ). R.S.D. values lower than $2.0 \%$ attested the precision of the method.

\section{Accuracy}

It was investigated by means of a standard addition experiment, at three concentration levels in triplicate $(n=9)$. The mean recovery of $101.56 \%$ (R.S.D. $=0.35 \%$ ) assured the method accuracy.
Specificity

No absorption band was found at $382 \mathrm{~nm}$ in the UV-Visible spectra of daidzein and glycitein, recorded after addition of $\mathrm{AlCl}_{3}$. The absence of chelatogenic systems in those compounds disables the reaction with $\mathrm{AlCl}_{3}$. Therefore, the method showed adequate specificity for genistein and its glycoside, regarding the other major isoflavones (daidzein and glycitein) in soy dry extracts samples.

\section{Robustness}

Statistical analysis showed no significant difference between results obtained employing analytical conditions established for the method and for experiments in which variations were introduced. Thus, the method showed to be robust for variable volumes of $\mathrm{AlCl}_{3}$ added, in the range of 0.5 to $1.5 \mathrm{~mL}$, as well as for two different suppliers of methanol used.

\section{Detection and quantitation limits}

The detection limit calculated using parameters of the calibration curve was $0.25 \mu \mathrm{g} / \mathrm{mL}$. In the spectrophotometric analysis of diluted solutions, it was possible to identify the absorption band at $382 \mathrm{~nm}$ in the concentration $0.15 \mu \mathrm{g} / \mathrm{mL}$, with a corresponding absorbance value of $0.003 \mathrm{~A}$. The quantitation limit determined based on the parameters of the calibration curve was $0.76 \mu \mathrm{g} / \mathrm{mL}$. However, a genistein standard solution at $0.40 \mu \mathrm{g} / \mathrm{mL}$ provided absorbance values around $0.006 \mathrm{~A}$, with adequate precision (R.S.D. $<2.0 \%$ ) and linearity and therefore, this value can be considered the quantitation limit of the method. Hence, detection and quantitation limits calculated by the parameters of the calibration curve were close, but slightly higher than the values obtained by the spectrophotometric analysis of diluted solutions.

\section{Analysis of soy dry extract samples}

Commercial samples of soy dry extracts employed as pharmaceutical raw material, standardized to contain $40 \%$ (w/w) of total isoflavones, were analyzed by both spectrophotometric and chromatographic methods. The results obtained by the spectrophotometric method correspond to both genistein and genistin contents, expressed as genistein. In the RP-HPLC analysis, the results are expressed as genistein content after hydrolysis, corresponding to the amounts of genistein and its hydrolyzed glycoside, genistin (Table 2).

Data on Table 2 indicate higher contents of genistein and genistin determined by spectrophotometry in comparison to the concentrations assayed by the RP-HPLC method. Analysis of the obtained results by

Table 2. Contents of genistein and genistin in soy dry extract samples obtained by spectrophotometric and chromatographic methods

\begin{tabular}{lcc}
\hline Sample & $\begin{array}{c}\text { UV-Visible method } \\
\text { Contents of genistein and } \\
\text { genistin, expressed as } \\
\text { genistein }(\% \pm \text { s.d. })\end{array}$ & $\begin{array}{c}\text { RP-HPLC method } \\
\text { Contents of genistein } \\
\text { after acid hydrolysis } \\
(\% \pm \text { s.d. })\end{array}$ \\
\hline 1 & $16.05 \pm 0.09$ & $12.79 \pm 0.29$ \\
$2 \mathrm{a}$ & $0.91 \pm 0.05$ & $0.56 \pm 0.04$ \\
$2 \mathrm{~b}$ & $3.30 \pm 0.06$ & $2.37 \pm 0.08$ \\
3 & $13.66 \pm 0.26$ & $10.36 \pm 0.18$ \\
4 & $14.71 \pm 0.22$ & $11.22 \pm 0.28$ \\
5 & $13.85 \pm 0.16$ & $9.93 \pm 0.28$ \\
6 & $0.63 \pm 0.04$ & $0.40 \pm 0.05$ \\
\hline
\end{tabular}

s. d. = standard deviation 
Student's $t$-test indicated statistically significant difference between genistein contents determined by spectrophotometry and RP-HPLC, for all assayed samples $(\mathrm{p}<0.05)$. However, a clear proportionality between the contents obtained by both methods can be observed in the analyzed samples. The different sample preparation procedures, including solvents and temperature, might contribute to this observed content variation between the UV-Vis and RP-HPLC methods. Besides, the content specifications are not similar; the result of the spectrophotometric method is expressed as genistein content, corresponding to the total content of genistein and genistin, while the results of the chromatographic method are expressed as genistein content after hydrolysis. Hence, these differences regarding the two method specifications may interfere in a direct comparison of the results and demonstrate the necessity of considering distinct specifications for each method.

The developed UV-Visible method showed to be selective regarding the other isoflavones present in higher amounts in soy dry extracts (daidzein and glycitein). However, such extracts may contain other flavonoids and phenylpropanoids in lower concentrations and we cannot discharge the potential interference of those compounds in the detection by the spectrophotometric method, making it less specific when compared to RP-HPLC. On the other hand, the spectrophotometric method is more economical, in terms of cost and time, than the HPLC method.

The analyzed extracts are standardized to contain $40 \%(\mathrm{w} / \mathrm{w})$ of total isoflavones; however, the contents of individual isoflavones are not controlled and may fluctuate due to the influence of several factors, including soy variety, period of crop collection and geographical location. ${ }^{4}$ Hence, the analyzed samples showed high variations in genistein contents assayed in both methods. Considering that differences in biological effects of individual isoflavones are well documented, and genistein is supposed to be the most active compound, ${ }^{22}$ such variations might interfere in the efficacy of soy extracts based treatments, whenever reduced amounts of genistein are found.

\section{CONCLUSIONS}

Reaction with aluminum chloride followed by UV-Visible detection was demonstrated to be a simple and suitable technique for quantitation of genistein and genistin in soy dry extract samples. The developed method complied with all validation parameters and showed to be feasible and of low cost. Hence, it can be applied by compounding pharmacies and small laboratories in routine quality control analyses or may be used as a preliminary assay to evaluate the genistein content in soy extracts.

\section{ACKNOWLEDGEMENTS}

The authors thank FAPEMIG, for financial support.

\section{REFERENCES}

1. Howes, L. G.; Howes, J. B.; Knight, B. C.; Maturitas. 2006, 55, 203.

2. Anderson, J. J. B.; Anthony, M. S.; Cline, J. M.; Washburn, S. A.; Garner, S. C.; Public Health Nutr. 1999, 2, 489.

3. Duncan, A. M.; Phipps, W. R.; Kurzer, M. S.; Best Pract. Res. Clin. Obstet. Gynecol. 2003, 17, 253.

4. Dixon, R. A.; Annual Rev. Plant Biol. 2004, 55, 225.

5. Wober, J.; Weisswange, I.; Vollmer, G.; J. Steroid Biochem. Mol. Biol. 2002, 83, 227.

6. Branham, W. S.; Dial, S. L.; Moland, C. L.; J. Nutr. 2002, 132, 658.

7. Delmonte, P.; Perry, J.; Rader, J. I.; J. Chromatogr., A 2006, 1107, 59.

8. Chen, L. J.; Zhao, X.; Plummer, S.; Tang, J.; Games, D. E.; J. Chromatogr., A 2005, 1082, 60.

9. Klejdus, B.; Mikelová, R.; Petrlová, J.; Potesil, D.; Adam, V.; Stiborová, M.; Hodek, P.; Vacek, J.; Kizek, R.; Kubán, V.; J. Agric. Food Chem. 2005, 53, 5848 .

10. Penalvo, J. L.; Nurmi, T.; Adlercreutz, H.; Food Chem. 2004, 87, 297.

11. Thompson, L. U.; Boucher, B. A.; Liu, Z.; Cotterchio, M.; Kreiger, N.; Nutr. Cancer 2006, 54, 184.

12. Kuo, H. W.; Ding, W. H.; J. Chromatogr., A 2004, 1027, 67.

13. Grace, P. B.; Taylor, J. I.; Botting, N. P.; Fryatt, T.; Oldfield, M. F.; Bingham, S. A.; Anal. Biochem. 2003, 315, 114.

14. Wang, C. C.; Prasain, J. K.; Barnes, S.; J. Chromatogr., B: Anal. Technol. Biomed. Life Sci. 2002, 777, 3.

15. César, I. C.; Braga, F. C.; Vianna-Soares, C. D.; Nunan, E. A.; Pianetti, G. A.; Condessa, F. A.; Barbosa, T. A. F.; Moreira-Campos, L. M.; J. Chromatogr., B: Anal. Technol. Biomed. Life Sci. 2006, 836, 74.

16. Kosalec, I.; Bakmaz, M.; Pepeljnjak, S.; Vladimir-Knezevic, S.; Acta Pharm. 2004, 54, 65.

17. British Pharmacopoeia, $5^{\text {th }}$ ed., Her Majesty's Stationary Office: London, 2005.

18. Farmacopéia Brasileira, $4^{\mathrm{a}}$ ed., Atheneu: São Paulo, 1988.

19. Mabry, T. J.; Markham, K. R.; Thomas, M. B.; The systematic identification of flavonoids, Springer-Verlag: New York, 1970.

20. Harbone, J. B.; Mabry, T. J.; Mabry, H.; The Flavonoids, Chapman and Hall: London, 1975.

21. Validation of Analytical Procedures: Methodology - ICH Harmonized Tripartite Guideline; International Conference on Harmonization of Technical Requirements for Registration of Pharmaceuticals for Human Use, 1996.

22. Kuiper, G. G. J. M.; Lemmen, J. G.; Carlsson, B.; Corton, J. C.; Safe, S. H.; Van Der Saag, P. T.; Van Der Burg, B.; Gustafsson, J.; Endocrinology 1998, 139, 4252. 